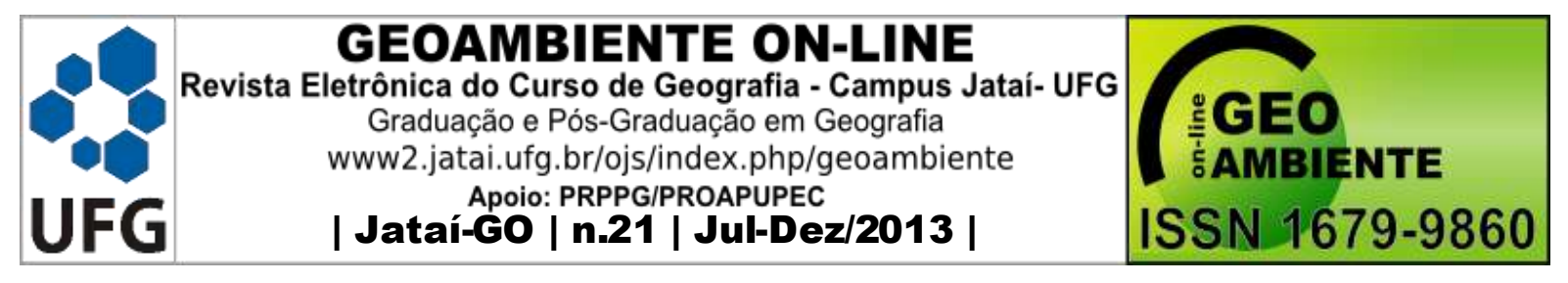

\title{
AS POLÍTICAS PÚBLICAS DE CONSERVAÇÃO NO ORDENAMENTO TERRITORIAL
}

Eliane Maria Foleto

\author{
Universidade Federal de Santa Maria, Prof ${ }^{a}$. Dr. ${ }^{a}$ Departamento Geociências/CCNE, \\ efoleto@gmail.com
}

\section{Resumo}

O processo desordenado de ocupação de áreas que deveriam ser conservadas, pela sua fragilidade à ocupação, como as Áreas de Preservação Permanente (APPs) - de margem, nascentes, encostas -, requer medidas eficazes para impor restrição de usos e ocupação, ordenando o espaço. Perante essa realidade, torna-se necessária a ação do poder público no sentido de proteger as áreas ambientalmente frágeis à ocupação, já definidas por lei, e as que ainda não foram ocupadas e mantêm ecossistemas naturais, buscando garantir a continuidade dos serviços ambientais, que trazem benefícios à qualidade de vida e protegem a população do risco. Nesse enfoque de áreas protegidas como ferramenta de ordenamento territorial, o artigo tem como objetivo analisar as políticas de conservação, que impõem restrições de uso, como a do Código Florestal e a que institui as Unidades de Conservação (UCs). Por se tratar de uma discussão teórica, o artigo foi elaborado através de uma pesquisa bibliográfica. Pode-se observar que as Políticas Públicas de Conservação, como a que define as APPs e as UCs, são um componente a mais no sistema de ordenamento territorial, que é um processo dinâmico que visa avaliar e planejar o uso do solo e o manejo dos recursos naturais, em várias escalas do nacional ao local, considerando o equilíbrio ecológico e a proteção do ambiente e da qualidade de vida da população.

Palavras-chave: Políticas públicas. Áreas protegidas. Ordenamento territorial.

\begin{abstract}
PUBLIC POLICIES OF CONSERVATION SPATIAL PLANNING

The disordered occupation process of areas that should be preserved in relation to their frailty because of occupation, such as Permanent Preservation Areas (APPs) - margin, springs, slopes
\end{abstract}

Artigo recebido para publicação em 26 de Outubro de 2013

Artigo aprovado para publicação em 28 de Dezembro de 2013 


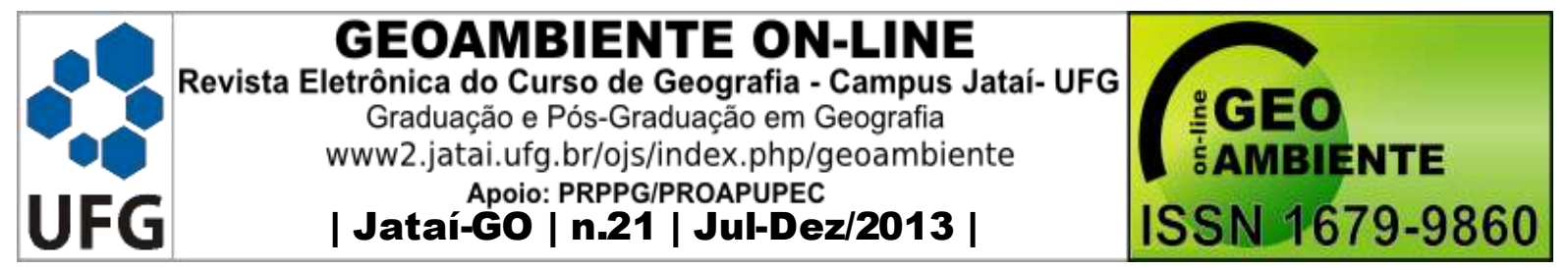

- requires effective measures to enforce restriction on uses and occupation with the purpose of ordering the space. Given this reality, the action of the government becomes necessary in order to protect the environmentally fragile areas of occupation, as defined by law, and also those that are not yet occupied and maintain natural ecosystems, seeking to ensure the continuity of the environmental services that bring benefits to the quality of life and protect the population against risk. In this approach of considering protected areas as a tool for spatial planning, the article aims to analyze the conservation policies that impose restrictions on use, such as the Forest Code and the one that establishes the Conservation Units (CUs). As this is a theoretical discussion, the article was written through investigation in the literature. It can be observed that the Public Policy for Conservation, as the one that defines the APPs and CUs, is an additional component in spatial planning system, which is a dynamic process with the aim of assessing and planning the land use and natural resource management at various scales from national to local, taking into consideration both ecological balance and protection of environment and quality of life.

Key words: Public Policy. Protected Areas. Spatial Planning.

\section{Resumen}

\section{LAS POLÍTICAS PÚBLICAS DE CONSERVACIÓN EN EL ORDENAMIENTO TERRITORIAL}

El proceso de ocupación de áreas que deberían ser consideradas frágiles como las Áreas de Preservación Permanente/APP: orillas, nacientes, laderas, requieren medidas eficaces para imponer restricciones de uso y ocupación y, de este modo, ordenar el espacio. Frente a esta realidad, es necesario la acción del poder público en el sentido de proteger las áreas ambientalmente frágiles a la ocupación, ya definidas en ley, y las que todavía no fueran ocupadas y mantienen ecosistemas naturales, a fin de garantizar la continuidad de los servicios ambientales, que benefician la calidad de vida, y protegen la población de riesgo. A través de este enfoque de áreas protegidas como instrumento de ordenamiento territorial, este artículo posee como objetivo analizar las políticas de conservación, que imponen restricciones de uso, como la del Código Forestal, y la que instituye las Unidades de Conservación. Como se trata de una discusión teórica, se elaboró el artículo, mediante una investigación bibliográfica, en la que se puede observar que las Políticas Públicas de Conservación, como la que define las Áreas de Preservación Permanente y las Unidades de Conservación son un componente más, 


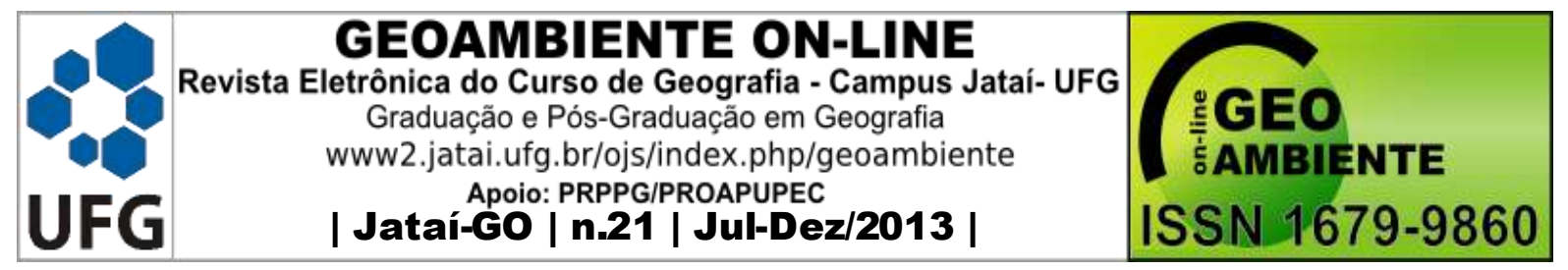

en el sistema de ordenamiento territorial, que es un proceso dinámico que visa evaluar y planear el uso del suelo y el manejo de los recursos naturales, en varias escalas del nacional al local, considerando el equilibrio ecológico, la protección del ambiente y la calidad de vida de la población.

Palabras Clave : Políticas Públicas. Áreas Protegidas. Ordenamiento Territorial

\section{Introdução}

O uso e a ocupação de áreas que são frágeis aos processos da dinâmica superficial da água promovem impactos ambientais e situações de risco à população. Perante essa realidade, tornam-se necessárias ações do poder público para a implantação das Políticas Públicas de Conservação e um planejamento ambiental territorial, articulando as áreas protegidas com as paisagens, visando a medidas de proteção e impondo restrição de uso e ocupação. Entre essas áreas a serem protegidas, estão as que apresentam remanescentes de ecossistemas naturais e as que, se ocupadas, pela dinâmica superficial da água, podem gerar risco à população, como as Áreas de Preservação Permanente (APPs): de encosta, margem e nascentes de rios. Assim, sob essa perspectiva, o artigo tem como objetivo analisar as principais Políticas Públicas de Conservação que interferem no ordenamento territorial, sob a ótica da restrição de uso e ocupação.

Entre as Políticas Públicas de Conservação, a de maior abrangência no território nacional é a do Código Florestal Federal, endossado pela maioria dos estados e municípios. Essa política impõe restrição de uso total nas APPs e permite o uso sustentável, na Reserva Legal (RL), da propriedade rural. Estas existem pelo efeito de lei e só poderão ser utilizadas em casos de interesse social ou utilidade pública, após autorização do órgão ambiental competente.

Já a política que define as Unidades de Conservação (UCs) atribui a responsabilidade de instituir essas áreas ao poder público municipal, estadual e federal, com o objetivo da conservação in situ de ecossistemas que possuam relevância ecológica. Define também dois grupos de unidades, de proteção integral e de uso sustentável, cada grupo composto por várias tipologias, diferentes quanto ao objetivo da conservação, posse da terra e gestão. $\mathrm{Na}$ maioria das tipologias, para a efetiva gestão, necessita-se do Plano de Manejo, a ser elaborado e discutido pelos Comitês Gestores. 


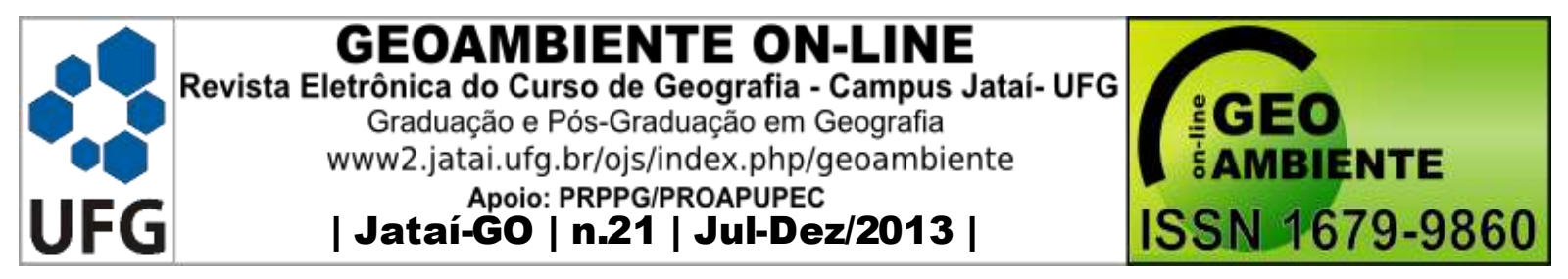

Em ambos os casos de áreas protegidas, estas interferem no ordenamento territorial e definem uma gestão diferenciada ao território municipal, e os Planos Diretores deverão respeitar as restrições impostas, visando à conservação ambiental. No caso das UCs, seu território poderá ser intermunicipal ou interestadual, dependendo do limite da unidade, que deve considerar o atributo a ser conservado; e terá como órgão gestor o que as instituiu, podendo ser federal/Instituto Chico Mendes de Conservação da Biodiversidade (ICMBio), estadual ou ainda municipal. A importância dessas políticas de conservação está em garantir a conservação e, consequentemente, a continuidade dos serviços ambientais, os quais trazem benefícios à qualidade de vida da sociedade.

\section{Pressupostos teóricos}

A ação do poder público interferindo no processo de ocupação do espaço, de forma a ordenar o território, visa atender, através de Áreas Protegidas, aos objetivos da Política Nacional de Meio Ambiente, Lei no 6.938/81, amparada pelo texto da Constituição de 1988, conforme dispõe o Art. 225: "Todos têm direito ao meio ambiente ecologicamente equilibrado, bem de uso comum do povo e essencial à sadia qualidade de vida, impondo-se ao Poder Público e à coletividade o dever de defendê-lo e preservá-lo para as presentes e futuras gerações." (BRASIL, 1988).

Para assegurar a efetividade desse direito, atribui-se ao poder público a responsabilidade de definir, em todas as unidades da Federação, espaços territoriais e seus componentes a serem especialmente protegidos, sendo a alteração e a supressão permitidas somente através de lei, vedada qualquer utilização que comprometa a integridade dos atributos que justifiquem a sua proteção. Além disso, cabe-lhe também a responsabilidade de proteger a fauna e a flora, vedadas, na forma da lei, as práticas que coloquem em risco sua função ecológica, provoquem a extinção de espécies ou submetam os animais à crueldade.

Designa-se como competência concorrente da União, dos estados, municípios e do Distrito Federal legislar sobre: florestas, caça, pesca, fauna, conservação da natureza, defesa do solo e dos recursos naturais, proteção do meio ambiente e controle da poluição, sendo que à União é assegurada a produção de normas gerais, deixando aos estados e aos municípios suplementar a legislação federal e a estadual no que couber, quando referir-se à área de interesse local. No entanto, o que se percebe é que, na maioria dos estados e municípios, ocorre uma repetição, cópia, das leis gerais, de âmbito federal. Os municípios não conseguem 


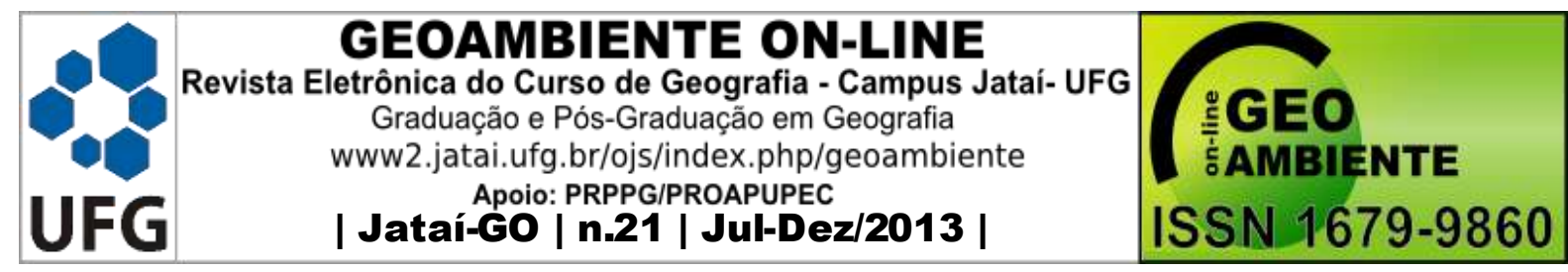

impor maior restrição de uso do que as normas já previstas na lei que institui o Código Florestal e têm dificuldade de incorporar novas áreas a serem protegidas, como as Unidades de Conservação.

A terminologia de áreas protegidas é abrangente. A princípio refere-se a áreas com restrições de uso, impondo uma gestão específica, que compreende diversas tipologias, como as Áreas de Preservação Permanente e a Reserva Legal, previstas pelo Código Florestal brasileiro (Lei $\mathrm{n}^{\mathrm{o}}$ 12.651/2012), as Unidades de Conservação (UCs), definidas pelo Sistema Nacional de Unidades de Conservação da Natureza (SNUC, Lei n ${ }^{\circ}$ 9.985/2000), e as Terras Indígenas, tipologia presente no Estatuto do Índio (Lei no 6.001/1973). Além das Unidades de Conservação, os municípios poderão instituir Áreas de Interesse Especial, determinação que se ampara legalmente na Lei $\mathrm{n}^{\circ}$ 10.257/01, do Estatuto da Cidade, que regulamenta os artigos 182 e 183 da Constituição Federal/88. Assim, cabe aos municípios, ao estabelecer sua política de uso do solo urbano/Plano Diretor, definir as diretrizes de forma a proteger, preservar e recuperar o meio ambiente natural e construído, o patrimônio cultural, histórico, artístico, paisagístico e arqueológico de seu território.

A União Mundial para a Natureza (The World Conservation Union - IUCN) define área protegida como uma superfície de terra ou mar especialmente consagrada à proteção e preservação da diversidade biológica, assim como dos recursos naturais e culturais associados, e gerenciada através de meios legais ou outros meios eficazes.

Considera-se aqui o conceito da IUCN para áreas protegidas, pois permite considerar a criação dessas áreas como uma estratégia de controle do território, devido às restrições de uso impostas, garantindo, assim, medidas preventivas. Conforme Cabral e Souza (2005), tais medidas seriam: interromper, em alguns casos, a atuação antrópica, de modo a permitir a manutenção e a recuperação de atributos naturais ou, em outros casos - de maneira concomitante ou não no mesmo espaço -, permitir o uso desses recursos, garantindo sua manutenção no longo prazo em condições regulares, minimizando, assim, em ambos os procedimentos, as respostas negativas da atuação antrópica.

\section{Políticas Públicas de Conservação Ambiental}

Os Espaços Territoriais a serem Especialmente Protegidos são materializados através das Áreas Protegidas que conservam o Meio Ambiente Ecologicamente Equilibrado e garantem a estrutura, função e dinâmica de um ecossistema através de restrições de usos. 


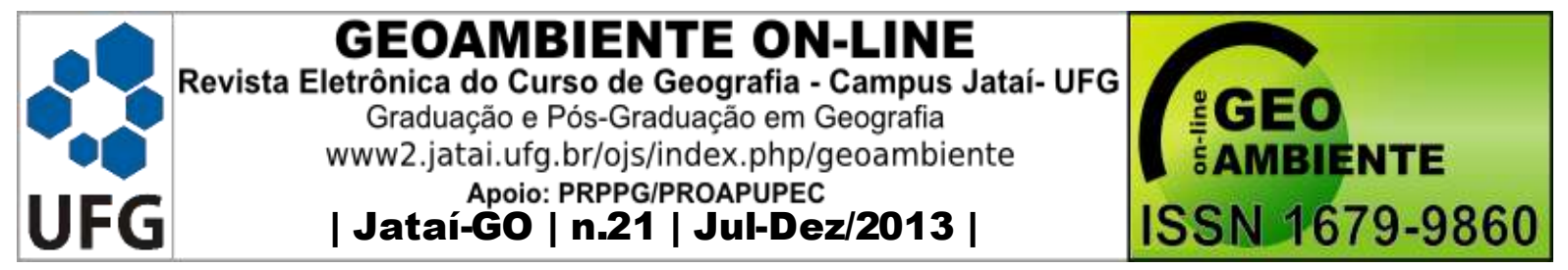

\section{Áreas Protegidas: Áreas de Preservação Permanente e Reserva Legal}

Entre essas Áreas Protegidas, têm-se as Áreas de Preservação Permanente e a Reserva Legal, instituídas pelo primeiro Código Florestal brasileiro - Lei Federal no 23.793/34, Lei ${ }^{\circ}$ 4.771/65, Lei $\mathrm{n}^{\circ} 7.754 / 89$ e, recentemente, Lei $\mathrm{n}^{\circ}$ 12.651/12 -, em todo o território nacional, sendo que nas diferentes leis houve a alteração da extensão das áreas. Já as Unidades de Conservação (UCs) regulamentadas - Lei no 9.985/00, SNUC - são instituídas pelo poder público.

A política do Código Florestal Federal - Lei no 12.651/12 - define no Art. $1^{\circ}$ que "As florestas existentes no território nacional e as demais formas de vegetação, reconhecidas de utilidade às terras que revestem, são bens de interesse comum a todos os habitantes do País, exercendo-se os direitos de propriedade com as limitações que a legislação em geral e especialmente esta Lei estabelecem. São áreas com restrição de uso em propriedade privada."

Para assegurar esse interesse comum a todos os habitantes, o Código Florestal define como Área de Preservação Permanente uma área de proteção integral, não podendo ser utilizada pelo proprietário, principalmente as áreas localizadas em margens e nascentes de rios, encostas e topo de morros, cobertas ou não por vegetação nativa, com a função ambiental de preservar recursos hídricos, a paisagem, a estabilidade geológica, a biodiversidade, o fluxo gênico de fauna e flora, bem como proteger o solo e assegurar o bem-estar das populações humanas. Ainda, estabelece os critérios da Reserva Legal, sendo que o percentual a ser conservado varia em função do tipo de bioma. Por Reserva Legal, entende-se a área localizada no interior de uma propriedade ou posse rural, excetuada a de preservação permanente, necessária ao uso sustentável dos recursos naturais, à conservação e reabilitação dos processos ecológicos, à conservação da biodiversidade e ao abrigo e proteção de fauna e flora nativas. Essas duas áreas possuem função, estrutura e dinâmica e aí se justificam as duas tipologias.

\section{A supressão de vegetação em Áreas de Preservação Permanente}

As APPs são de proteção integral, e o uso das áreas com a supressão de vegetação só poderá ocorrer em casos que a Resolução no 369/06 do Conselho Nacional de Meio Ambiente (Conama) defina como de utilidade pública ou interesse social, devidamente caracterizados e motivados em procedimento administrativo, e, quando não existir outra alternativa técnica, por meio de autorização do órgão ambiental competente. Além da utilidade pública ou interesse 


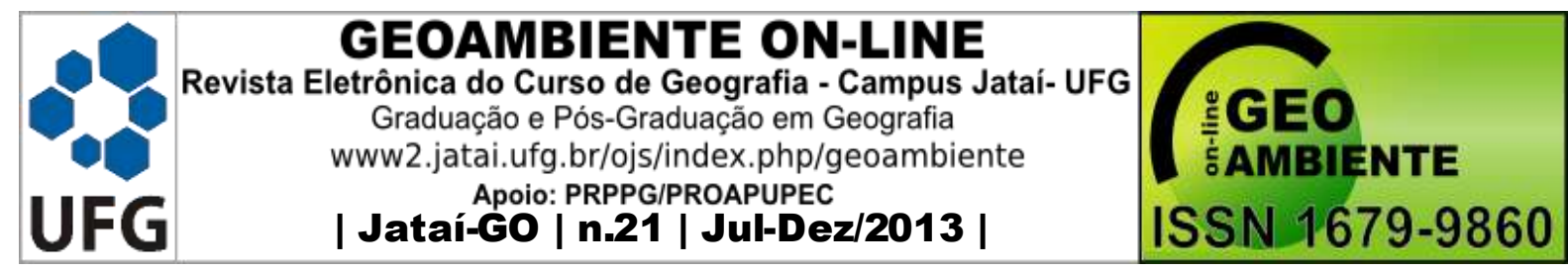

social, a resolução define os casos excepcionais em que o órgão ambiental pode autorizar a intervenção ou supressão de vegetação. Entre as atividades permitidas estão as consideradas de baixo impacto ambiental, como: trilhas ecoturísticas, ciclovias; pequenos parques de lazer, excluídos parques temáticos ou similares; acesso aos corpos de água e travessia deles, mirantes, equipamentos de segurança, lazer, cultura e esporte, bancos, sanitários, chuveiros e bebedouros públicos, e rampas de lançamento de barcos e pequenos ancoradouros.

Nos casos de utilidade pública e interesse social, a Resolução no 369/06 define: como utilidade pública: a) as atividades de segurança nacional e proteção sanitária; b) as obras essenciais de infraestrutura destinadas aos serviços públicos de transporte, saneamento e energia; e c) demais obras, planos, atividades ou projetos previs tos em resolução do Conama; e como interesse social: a) as atividades imprescindíveis à proteção da integridade da vegetação nativa, tais como: prevenção, combate e controle do fogo, controle da erosão, erradicação de invasoras e proteção de plantios com espécies nativas, conforme resolução do Conama; b) as atividades de manejo agroflorestal sustentável praticadas na pequena propriedade ou posse rural familiar, que não descaracterizem a cobertura vegetal e não prejudiquem a função ambiental da área; e c) demais obras, planos, atividades ou projetos definidos em resolução.

Com esse fim, o Conama aprovou situações específicas de áreas urbanas, que caracterizam utilidade pública ou interesse social, nos seguintes casos: utilidade pública, entre outros, a implantação de área verde pública em área urbana; obras públicas para implantação de instalações necessárias à captação e condução de água e de efluentes tratados; e interesse social, entre outros, a regularização fundiária sustentável de área urbana.

Vale destacar que, além das Áreas de Preservação Permanente e Reserva legal, que existem pelo efeito de lei e cujos proprietários têm a obrigação de preservar, existe a possibilidade de instituir na propriedade ou em parte dela uma Reserva Particular do Patrimônio Natural (RPPN), tipologia de Unidade de Conservação do Grupo de Uso Sustentável, sendo que, em alguns estados da Federação, como o Rio Grande do Sul, essas Unidades são de Proteção Integral. Após a implantação junto ao órgão ambiental, o proprie tário obtém alguns benefícios, como a isenção de Imposto Territorial Rural.

\section{Áreas Protegidas: Unidades de Conservação}

As UCs e suas diferentes categorias de manejo já existiam no Brasil muito antes da criação do SNUC, instituído pela Lei no 9.985/2000, como, por exemplo, o Parque Nacional de 


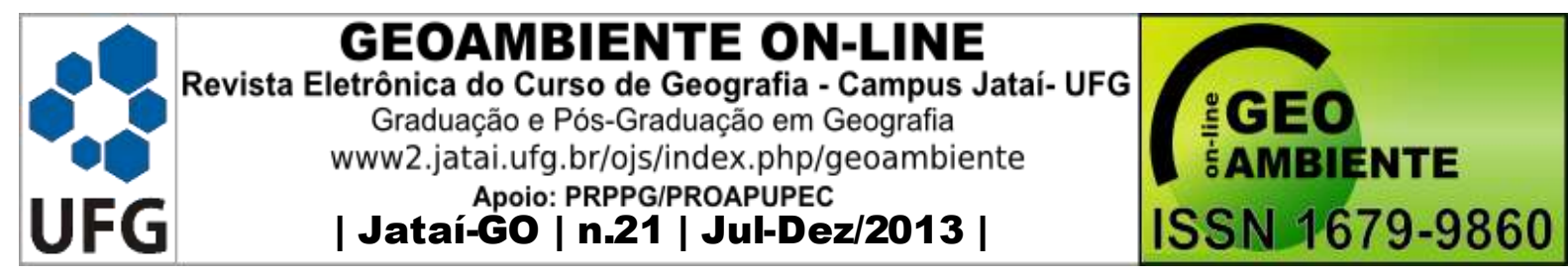

Itatiaia, criado em 1937, considerado a primeira UC do país. A Lei do SNUC surgiu como uma forma de organizar, sistematizar e normatizar a implantação das áreas protegidas no Brasil, sendo um marco político importante na criação e gestão de UCs. O SNUC define Unidade de Conservação como o espaço territorial e seus recursos ambientais, incluindo as águas jurisdicionais, com características naturais relevantes, legalmente instituído pelo poder público, com objetivos de conservação e limites definidos, sob regime especial de administração, ao qual se aplicam garantias adequadas de proteção.

A Lei do SNUC organiza as 12 categorias de UCs e as classifica em dois grupos de manejo, de acordo com seus objetivos e características:

- Grupo das Unidades de Proteção Integral: áreas que têm como objetivo preservar a natureza, admitindo-se o uso indireto dos recursos naturais em algumas categorias, estando protegidas de interferências predatórias. Dentro desse grupo, enquadram-se: Estação Ecológica, Reserva Biológica, Parque Nacional, Monumento Natural e Refúgio da Vida Silvestre. Assim, segundo seus objetivos, as atividades permitidas nas áreas dessas UCs são educação ambiental, visitação, pesquisa científica, turismo e outras que não envolvam a exploração direta de seus recursos;

- Grupo das Unidades de Uso Sustentável: áreas que pretendem conciliar a conservação da natureza com o uso sustentável de parte de seus recursos naturais, permitindo-se a exploração destes de forma equilibrada, a fim de garantir sua manutenção a longo prazo e minimizar os impactos negativos da atuação antrópica. Estão presentes nesse grupo as categorias: Área de Proteção Ambiental, Área de Relevante Interesse Ecológico, Floresta Nacional, Reserva Extrativista, Reserva da Fauna, Reserva de Desenvolvimento Sustentável e Reserva Particular do Patrimônio Natural. As atividades previstas para essas áreas são menos restritivas: educação ambiental, pesquisa científica, turismo, exploração sustentável de florestas, frutos e sementes, agricultura sustentável, pesca e caça para subsistência, entre outros, sempre visando à garantia de sustentabilidade dos recursos.

Sendo assim, as UCs produzem espaços de dinâmicas específicas e com uma administração diferenciada, o Comitê Gestor, sendo que a criação das UCs é considerada importante estratégia de ordenamento territorial pelo Estado, na medida em que estabelece limites e restrições para o uso e a ocupação do espaço (MEDEIROS, 2006; MEDEIROS; YOUNG, 2011). Essas áreas devem ser implementados e geridas com o propósito a que foram 


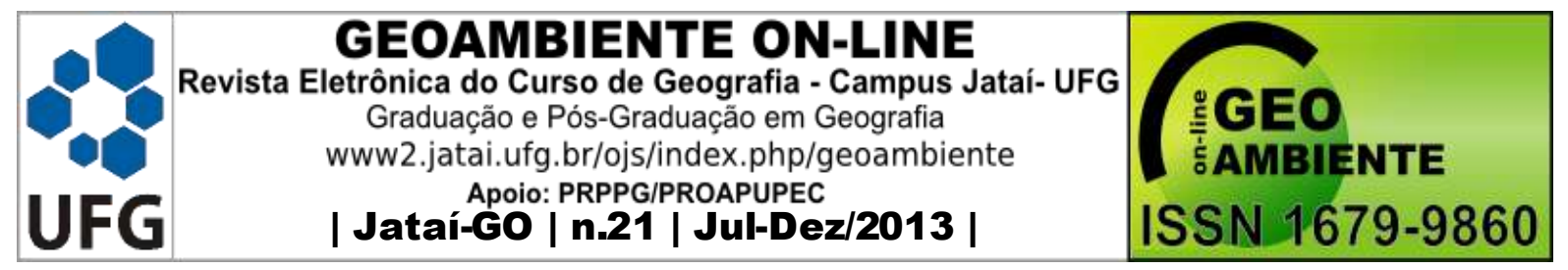

criadas, fornecer à população bens e serviços, como, por exemplo, a manutenção dos serviços ecossistêmicos, a ciclagem dos nutrientes, o controle de pragas e a polinização.

\section{Plano de Manejo: efetividade na proteção?}

As Áreas Protegidas do SNUC possuem uma característica que as diferencia das demais: a obrigatoriedade de um Plano de Manejo, a ser elaborado e discutido, quando de uso sustentável, junto às comunidades envolvidas, pelo órgão ambiental proponente, que estabelece normas e regras de uso. Quando da proteção integral, o órgão ambiental estabelece limites de uso e ocupação.

Nos Planos de Manejo, estarão dispostas as ações possíveis àquela área, para que o seu uso seja condizente com a proposta da unidade e com a categoria de manejo na qual ela se encontra no SNUC. De acordo com a Lei Federal no 9.985/2000, que institui o SNUC, um Plano de Manejo refere-se a: documento técnico mediante o qual, com fundamento nos objetivos gerais de uma unidade de conservação, se estabelecem o seu zoneamento e as normas que devem presidir o uso da área e o manejo dos recursos naturais, inclusive a implantação das estruturas físicas necessárias à gestão da unidade (BRASIL, 2000).

Sendo assim, uma das principais finalidades do Plano de Manejo é buscar a preservação da biodiversidade e dos recursos hídricos, a proteção de espécies raras, endêmicas ou em risco de extinção; visar ao favorecimento do fluxo gênico entre as áreas protegidas; manter as paisagens de extraordinária beleza cênica; incentivar pesquisas, a prática da educação ambiental e o turis mo ecológico e de recreação; entre outras.

Além de promover o manejo da área a partir de ações planejadas, esse documento visa cumprir os objetivos estabelecidos na sua criação, definir objetivos específicos para a área, orientar o investimento financeiro da unidade, divulgá-la e, entre outros, estabelecer as intensidades de uso a partir do zoneamento (FERREIRA, 2004).

No estudo de áreas protegidas, pode-se identificar muitos conflitos em função das diferentes restrições de uso impostas por legislações distintas, que, apesar de legislarem sobre o mesmo objeto, possuem objetivos específicos, como as Áreas de Preservação Permanente, Código Florestal/65/89, Lei de Uso do Solo Urbano/75, Resoluções Conama nº 302, 303/02 e a 369/06, além das Unidades de Conservação e de regulamentações específicas de uso e ocupação do solo municipais. 


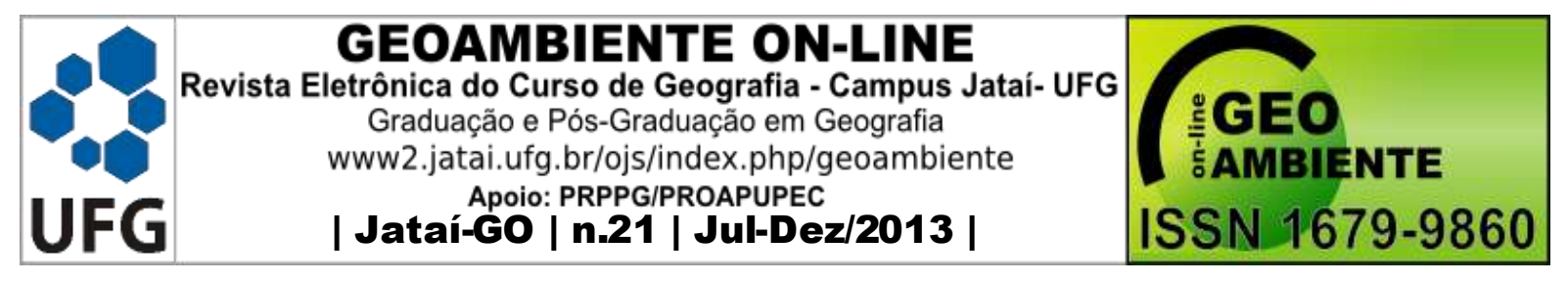

O fato é que o Código Florestal e as resoluções subsequentes não conseguiram atingir seus objetivos preservacionistas, e os proprietários continuam a ocupar as margens dos cursos d'água e a área destinada à Reserva Legal. Nas cidades, o caso não é diferente, a demanda por espaços gera a ocupação de APPs, que é uma das questões que têm gerado maior polêmica na atualidade do direito ambiental brasileiro.

Os principais problemas para a implantação e consolidação de áreas a serem protegidas estão na restrição de uso em uma sociedade com demanda crescente por espaços, na centralização e na falta de padronização de conduta para a criação, implantação e fiscalização das UCs, deixando-as a cargo do órgão ambiental. Parece que até então os gestores municipais não entenderam a importância de instituir áreas protegidas em seus territórios; preocupam-se demasiadamente com a restrição de uso, esquecendo-se dos serviços ambientais prestados por essas áreas.

Outra questão é que os diferentes setores da administração pública planejam as ações de forma fragmentada, desconsiderando que as questões ambientais devem ter um tratamento integrado, condição indispensável à gestão eficiente do meio ambiente.

Por fim, cabe salientar que a sobrevivência da humanidade e a continuidade da vida no planeta dependem da preservação e conservação do meio ambiente, fazendo-se necessária a implantação de áreas a serem protegidas com restrições de uso. Mas, para que isso ocorra, é necessária a conscientização do poder público e da sociedade de forma geral, incluídos, necessariamente, os proprietários de terras privadas, que devem estar conscientes da importância da existência dessas áreas para a preservação dos serviços ambientais.

\section{Referências:}

BRASIL. Casa Civil da Presidência da República. Lei Federal n. 4.771, de 15 de setembro de 1965, que institui o novo Código Florestal. 1965. Disponível em: <http://www.

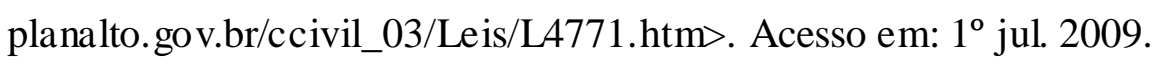

BRASIL. Constituição (1988). Constituição da República Federativa do Brasil: promulgada em 5 de outubro de 1988. 1988. Disponível em: $<$ http://legis.senado.gov.br/legislacao/ListaPublicacoes.action?id=102408>. Acesso 25 nov. 2013.

BRASIL. Lei n. 9.985, de 18 de julho de 2000. Institui o Sistema Nacional de Unidades de Conservação da Natureza. Presidência da República, Casa Civil, Brasília, DF, 18 jul. 2000. 


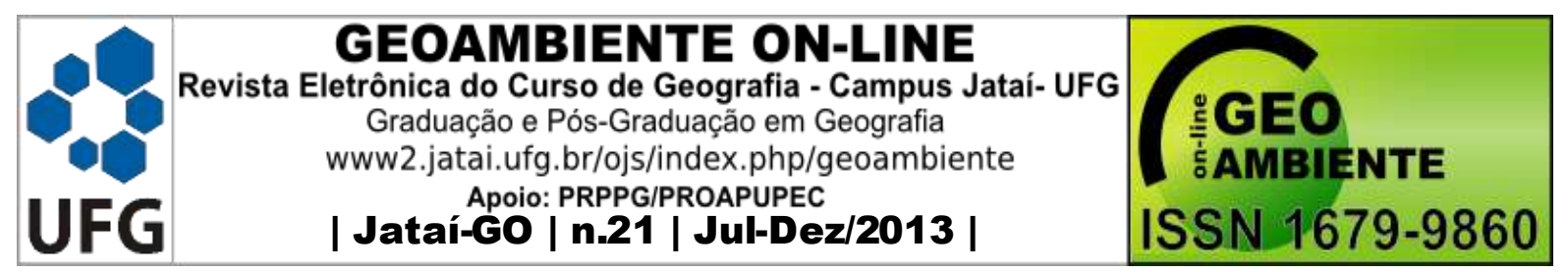

Disponível em: <http://www.planalto.gov.br/ccivil_03/LEIS/L9985.htm> Acesso em: 5 out. 2010.

BRASIL. Lei n. 12.651, de 25 de maio de 2012. Dispõe sobre a proteção da vegetação nativa; altera as Leis $\mathrm{n}^{\mathrm{os}}$ 6.938, de 31 de agosto de 1981, 9.393, de 19 de dezembro de 1996, e 11.428, de 22 de dezembro de 2006; revoga as Leis $n^{\text {os }} 4.771$, de 15 de setembro de 1965, e 7.754, de 14 de abril de 1989, e a Medida Provisória n⿳0 2.166-67, de 24 de agosto de 2001; e dá outras providências. 2012. Disponível em: < http://www.planalto.gov.br/ccivil_03/_Ato20112014/2012/Lei/L12651.htm>. Acesso 25 nov. 2013.

CABRAL, N. R. A. J.; SOUZA, M. P. Área de proteção ambiental: planejamento e gestão de paisagens protegidas. 2. ed. São Carlos: RiMa, 2005.

FERREIRA, L. M.; CASTRO, R. G. S. de; CARVALHO, S. H. C. de. Roteiro Metodológico para a Elaboração de Planos de Manejo para Reservas Particulares do Patrimônio Natural. IBAMA: Brasília, 2004.

MEDEIROS, R. Evolução das tipologias e categorias de áreas protegidas no Brasil. Ambiente \& Sociedade, Campinas, n. 1, p. 41-64, jan./jun., 2006. Disponível em: <http://www.scielo.br/pdf/asoc/v9n1/a03v9n1.pdf>. Acesso em: 17 abr. 2011.

MEDEIROS, R.; YOUNG, C. E. F. Contribuição das unidades de conservação brasileiras para a economia nacional: relatório final. Brasília: Unep-WCMC, 2011. 120 p. Disponível em: <http://www.mma.gov.br/estruturas/sbf2008_dap/_publicacao/149_publicacao080620111 00539.pdf>. Acesso em: $1^{\mathrm{o}}$ jun. 2011. 